\title{
Sen and Aristotle on Wellbeing
}

\author{
Bill Ransome
}

\begin{abstract}
A significant body of research and analysis concerning wellbeing has emerged across a number of social research disciplines, yet the concept of wellbeing does not admit of any unified meaning. Philosophical accounts of wellbeing are traditionally divided into three categories: hedonistic, desire-satisfaction and objective list theories, reflecting longstanding doctrinal divisions in normative ethics. Rejecting the foundational monism associated with these approaches, Amartya Sen has proposed a pluralist 'capabilities' approach to personal wellbeing based on freedom of choice and the Aristotelian notion of a 'function'. Recent Australian wellbeing research also shows promising signs of moving beyond reductive income-based metrics towards plural indicators of poverty and social disadvantage. This paper reprises Aristotle's distinctive account of perfect wellbeing (eudaimonia) in the Nicomachean Ethics and investigates Sen's approach in its light, suggesting that future Australian research in the spirit of Sen's pluralism may benefit from Aristotelian insights into the 'thickness' of freedom implicated in personal wellbeing.
\end{abstract}

Keywords: well-being, Sen Amartya, capability, Aristotle 


\section{Philosophical Theories of Wellbeing}

Philosophical analyses of wellbeing belong in the branch of ethics, where 'wellbeing' is taken generally to mean what is good for a person overall. Beyond this basic description, however, accounts of the nature and conditions of personal wellbeing vary significantly. Theories of wellbeing fall into three traditional categories, which to some extent mirror long established divisions between opposing schools of thought in normative ethics. Hedonistic theories of wellbeing focus on the intrinsic value of certain psychological states, holding that what is good for a person overall is the greatest achievable balance of pleasure over pain (Crisp 2006). Desire-satisfaction theories hold that wellbeing consists in the satisfaction of a person's desires or preferences (Olsaretti 2006). Both hedonistic and desire-satisfaction theories of wellbeing source their evaluative foundations in the utilitarian ethical tradition, and together dominate the evaluative foundations of contemporary wellbeing research. ${ }^{1}$

Utilitarian approaches to wellbeing are often contrasted with objective list theories, whose proponents reject the reduction of wellbeing to utility (Griffin 1986). Objective list theories propose that certain objective conditions define personal wellbeing, and do not necessarily reject the inclusion of happiness and desire satisfaction: there is nothing in principle preventing an objective list theory from including happiness or preference satisfaction on its list of objective wellbeing values, since it is chiefly the reduction of wellbeing to utility without remainder to which they object. Objective list theories usually owe their evaluative origins to varieties of deontology, and especially to the natural law and human rights traditions in moral and political philosophy (Finnis 1980). Contemporary virtue ethical accounts of human wellbeing that trace their roots to Aristotelian ethics also constitute an objective list rather than a hedonistic or desire-satisfaction theory (Hursthouse 1999).

A fourth approach has recently emerged that shifts discussion away from the traditional theoretical presumption of foundational monism, towards a more flexible pluralist approach to personal wellbeing. ${ }^{2}$ Perhaps the most prominent and philosophically sophisticated of pluralist accounts is the freedom-based 'capabilities' approach developed by Amartya Sen (1985, 1987, 1992, 1999a, 1999b, 2008). Notably, Sen's account of wellbeing borrows its other central concept, that of a 'function', from the ancient Greek philosopher Aristotle. After briefly surveying an example of the pluralism emerging in Australian wellbeing research, this paper reprises Aristotle's distinctive account of perfect wellbeing (eudaimonia) in the Nicomachean Ethics and investigates Sen's capabilities approach to wellbeing in its light. The paper concludes with the suggestion that

\footnotetext{
${ }^{1}$ For example, in psychological research on subjective wellbeing, see Eid and Larsen (2007); in welfare economics, see Hausman (2008) and especially Hausman and McPherson (2008).

${ }^{2}$ A normative theory is foundationally monist when it reduces all other values to a single evaluative foundation, such as standard forms of utilitarianism, natural law theory and Kantian deontology, which reduce value to utility, natural goodness and duty respectively. A foundationally pluralist theory allows for the coexistence of different values without insisting on their ultimate reduction to a single evaluative foundation.
} 
future wellbeing research in the spirit of Sen's capabilities approach may benefit from aretaic Aristotelian insights into what might be called the 'thickness' of freedom implicated in personal wellbeing. ${ }^{3}$

\section{Plural Indicators of Social Disadvantage in Australia}

The movement towards pluralist philosophical approaches to the concept of wellbeing has an emerging corollary in recent Australian social research. For example, Saunders et al. (2008) have proposed a new plural approach to measuring social disadvantage in Australia, which seeks to include broader dimensions of deprivation and social exclusion going beyond conventional definitions of poverty based narrowly on income. ${ }^{4}$ In part answering a challenge to incorporate more meaningful measures of the range of valuable resources that people actually command, the study sought to develop a concept of poverty "grounded in the conditions faced by those who experience it" and that better reflects "the lived realities of poverty" in Australia (Saunders et al. 2008: 1767).

The two-stage research study sought to glean the views of disadvantaged people directly, and 'to generate a new body of evidence designed to broaden our understanding of deprivation ('missing out') and social exclusion (being 'left out') in an Australian context' (Saunders et al. 2008: 179). Focus groups with community sector clients and agency staff aimed to glean "how low-income Australians experience and perceive poverty, deprivation and exclusion, and what they (and agency staff) regard as the necessary ingredients of a decent life in Australia today" (180). A subsequent random-sample survey of Australian adults drew from the focus group results and previous Australian, British and New Zealand deprivation and exclusion studies. In this study deprivation was defined as "an enforced lack of socially perceived necessities (or essentials)" (177) and the key question concerned a lack of economic resources: if the respondent considered something essential but did not have it, was this because they could not afford it? (180-181). Social exclusion, on the other hand, was taken to refer to the complex and multidimensional problems of non-participation in key societal activities (178-179), and in the survey referred to perceived essentials - activities, services, capacities - not concerned with affordability.

The study unearthed a rich informational landscape of the resources people consider essential for personal wellbeing in the Australian context, including 26 deprivation-related indicators ('medical treatment if needed', 'warm clothes and bedding', 'a substantial meal at least once a day') and 27 exclusion-related indicators ('no regular contact with other people', 'did not participate in

\footnotetext{
3 The distinction between 'aretaic' and 'deontic' concepts is due to Slote (2001). 'Aretaic' ethics focus on qualities of people, in opposition to 'deontic' ethics which focus on principles of conduct.

4 This approach uses plural value information for assessing poverty and social disadvantage, leaving aside the question of plural or monist evaluative foundations (Sen 1985). To this extent, the plural metrics used by Saunders, Naidoo, and Griffiths (2008) may ultimately be based, for example, on a desire-satisfaction theory of overall human well-being.
} 
community activities', 'does not have a social life', 'could not go out with friends and pay their way') (Saunders et al. 2008: 182-7). By setting a threshold of multiple deprivation ( 3 or more conditions) and exclusion ( 7 or more indicators) in combination with a traditional income-based poverty indicator, the study measured the overlaps between them, identifying a core group in the Australian community who are "facing a high level of severe, multidimensional disadvantage" (190). This study exemplifies a promising broadening and deepening, consonant with Sen's consistent advocacy of an open and plural conception of personal wellbeing that is under way in Australian wellbeing research.

\section{Aristotle on Wellbeing: Ergon and Eudaimonia}

Sen's approach to wellbeing borrows some of its central elements from Aristotle. Sen seeks to ground his theory of wellbeing in the Aristotelian notion of a 'function':

The primary feature of wellbeing can be seen in terms of how a person can 'function', taking that term in a very broad sense. I shall refer to various doings and beings that come into this assessment as functionings. These could be activities (like eating or reading or seeing), or states of existence or being, e.g., being well nourished, being free from malaria, not being ashamed by the poverty of one's clothing or shoes (to go back to a question that Adam Smith discussed in his Wealth of Nations) (Sen 1985: 197-8).

Aristotle's main account of a human function, or ergon, is found in the Nicomachean Ethics (Aristotle, EN 1097b23-1098a21). Eudaimonia or 'human flourishing' (also translated potentially misleadingly as 'happiness') represents the chief human good: perfect wellbeing. ${ }^{5}$ Like Sen, Aristotle accentuates the active element of life as it is being lived, insisting that the flourishing person "both lives well and does well; for happiness has virtually been defined as a sort of living well and doing well” (EN 1098b21-2). Aristotle introduces the concept of an ergon or 'function' in the context of describing the variety of resources the achievement of eudaimonia requires:

For just as for a flute player, or a sculptor, or any expert, and generally for all those who have some characteristic function [ergon] or activity, the good - their doing well - seems to reside in their function, so too it would seem to be for the human being, if indeed there is some function that belongs to him (Aristotle, EN 1097b26-8).

The human function for Aristotle is closely associated with our possession of reason, is only fulfilled in a life of activity in accordance with reason "or at least not apart from it" (EN 1098a8-9) and excellence (arête) (EN 1098a16-17) in practical choice or decision-making (prohairesis). Engaging in such activity

5 'Chief' in this sense is also variously translated as 'primary', 'best' or 'highest' (Broadie 2002: 9). 
over a complete lifetime constitutes endaimonia (EN 1098a4-21). To describe someone as eudaimon "is to imply that the person is admirable, even enviable, an exemplar of life at its best" (Broadie 2002: 12). It is important to note here that Aristotle distinguishes between three distinct kinds of personal resources that life at its best requires: external goods, goods of the body, and goods of the soul (EN 1098b13-15). External goods are the various resources and possessions a person requires as the material foundations for living well - the achievement of wellbeing is impossible "without resources... as if by means of tools" (EN 1099a 33) - and good health and the avoidance of life-marring bad fortune are also requirements of eudaimonia (EN 1099a31-1099b8).

Yet the goods of the soul - its excellences - are not just necessary conditions or tools for living well, as other goods are, but constitute the central active element of eudaimonia: "the human good turns out to be activity of soul in accordance with excellence" (EN 1098a16-17). On the other hand, feelings of pleasure and happiness, and the possession of bodily health and other desirable goods popularly identified with wellbeing, are regarded as various signs and consequences of living in accordance with excellence. When people are functioning perfectly in accordance with excellence, they take intrinsic pleasure in their excellent activity, "So their life has no need of pleasure in addition, like a piece of jewellery fastened on, but contains pleasure within itself" (EN 1099a15-17). For Aristotle, then, the achievement of perfect wellbeing is much more a matter of acquiring, maintaining and expressing excellence - of cultivating internal resources for living well - than the achievement of happiness and pleasure, good health, or the possession of external resources such as wealth, possessions and social prestige. So although the achievement of perfect wellbeing still requires many other goods (EN 1099a31-b8) and although a life of eudaimonia is indeed pleasant and happy, it is arête or excellence with which the achievement of personal wellbeing (eudaimonia) is most clearly identifiable (EN 1098b30-1099a31).

Excellence in the sense required for perfect Aristotelian wellbeing divides into two categories: intellectual excellence and excellence of character. While intellectual excellences can be inculcated in people as a matter of direct teaching, character excellences are more subtle and difficult to acquire. The latter are states of character - permanent dispositions acquired and entrenched through habituation - that express themselves in reliably excellent practical choice (prohairesis) throughout a lifetime (EN 1106b36). Aristotle's account of character excellences situates them in the various specific spheres of human life and activity in which they are required for the maintenance of personal wellbeing. For example, courage (andreia) is manifested in excellent response to circumstances of fear and confidence, and moderation (sophrosune) in relation to appetite and pleasure-seeking. Open-handedness (eleutheriotes) and munificence (megaloprepeia) are manifested with respect to financial affairs, mildness (praotes) with respect to anger, greatness of soul (megalopsuchia) with respect to questions of self-worth, and other personal and social excellences are related to symbols of social status, pleasing and displeasing others, 
self-representation, leisure, wit and humour, and so on (Broadie 2002: 23-37). For each sphere of life where personal wellbeing is at stake, the eudaimōn commands internal resources for reliably excellent response.

Aristotle does not claim to identify a complete set of human excellences, since his characterisation of each excellence is only intended as a sketch of how the eudaimon can generally be expected to respond in the kinds of conditions faced in various spheres of life and activity with relevance to wellbeing. This "underlying material" of human life is not conducive to exacting precision (EN 1094b13-1095a13) and, as Broadie observes, "An ideally developed character may view all circumstances as simply posing the identical question, 'What is called for in this situation?'” (Broadie 2002: 23). Completing perfect wellbeing is a hybrid element of intellectual excellence. Organically unified with and completing each excellence of character in a flourishing life for Aristotle is phronèsis or 'practical wisdom' - also translated as 'prudence' - an intellectual excellence disposing its possessor to exceptional perception of particulars and deliberation about what is best (EN 1140a25-33). The phronimos expertly deploys practical reason, and commands a full set of internal resources, skills and abilities to make reliably excellent choices from among the plural ends, circumstances, and fine-grained particularities of everyday life. The phronimos achieves perfect wellbeing through eupraxia: quite literally "doing well" or achieving "good-in-the-action-itself" (EN 1140b6-7; Broadie 2002: 48). However, the possession of all the excellences with practical wisdom in a unified character is exceedingly rare: its acquisition is extremely difficult, and there are many ways of going wrong and acquiring bad characteristics that instead tend to reinforce ill-being (EN 1109a24-b27). For the majority of people, there is a correspondingly less exalted but achievable form of wellbeing involving the central characteristic of enkrateia or self-control, which involves reliably choosing well in the face of often countervailing circumstances and the pervasive temptations of akrasia or un-self-control (EN 1145a15-1154b35).

\section{Sen's Capabilities Approach to Wellbeing}

Sen's adaptation of Aristotle's function argument does not take up Aristotle's close association of wellbeing with excellence - Sen associates the concepts of function and wellbeing more closely with the other categories of goods - but it is nevertheless recognisably Aristotelian in basic form. In Sen's terminology external goods are 'commodities' whose utilisation via 'functionings' by and large determines the realisation of personal value and, ultimately, the achievement of wellbeing. A 'functioning' is a pattern of activity or way of being, which represents a practical achievement of its possessor: "what he or she manages to do or to be. It reflects, as it were, a part of the 'state' of that person" (Sen 1999b: 7). The state of a person, literally his or her 'being', is given by his or her currently 'achieved functions': the successful combination of the vector of commodities possessed by that person $(x i)$ with a function "converting a commodities vector into a vector of characteristics of those commodities" $(c i)$ and a utilisation function "reflecting one pattern of use 
of commodities" that that person can actually make $(f(\cdot))$ (Sen 1999b: 7). A person's being $(b i)$, with active choice of utilisation function $f i(\cdot)$ and given his or her commodity vector $x i$, is given by:

$$
b i=f(c(x i))(\text { Sen 1999b: 7). }
$$

Sen describes this person's wellbeing as "an evaluation of this bi, indicating the kind of being he or she is achieving," or his or her 'valuation function' (vi):

$$
v i=b i(f(c(x i)))(\operatorname{Sen} 1999 \mathrm{~b}: 8) \text {. }
$$

The overall set of functioning vectors "feasible for a person" given commodity set $x i$ and overall utilisation function set Fi is given by the set Pi(xi):

$$
P i(x i)=[b i \mid b i=f i(c(x i)) \text {, for some } f(\cdot) \in F i](\text { Sen 1999b: 8). }
$$

The concepts of freedom and capability enter Sen's account through the addition of a choice function, restricted by the set of available commodity vectors $(X i)$, in a set of "feasible functioning vectors $Q i(X i)$ ":

$$
\begin{aligned}
& Q i(X i)=[b i \mid b i=f i(c(x i)), \text { for some } f(\cdot) \in F i \text { and for some } \\
& x i=X i] \text { (Sen 1999b: 9). }
\end{aligned}
$$

Qi represents a person's eponymous 'capabilities' on Sen's theory, and Qi(Xi) his or her freedom of choice:

$Q i(X i)$ represents the freedom that a person has in terms of the choice of functionings, given his personal features Fi (conversion of characteristics into functionings) and his command over commodities $X i$ ('entitlements'). Qi can be called the 'capabilities' of person i given those parameters. It reflects the various combinations of functionings ('beings') he can achieve (Sen 1999b: 9).

The overall wellbeing a person can achieve, given his or her set of achievable 'beings' $b i$ and the valuation function $v i(\cdot)$, is then given by the set $V i$ :

$$
V i=[v i \mid v i=v i(b i) \text {, for some bi in Qi] (Sen 1999b: 9). }
$$

\section{Wellbeing and Freedom of Choice}

Sen is careful to caution against potential misinterpretation of the capabilities-based definition of wellbeing. It is not to be read as dictating that wellbeing will necessarily be maximised - 'the highest value of $v i$ in $V i$ ' - since the motive of maximising wellbeing is only one among many, especially given "other possible objectives and possible 'deontological' requirements (related, say, to one's obligations to others)" (Sen 1999b: 9). ${ }^{6}$ Yet Sen also admits that if people's wellbeing were to be identified reductively with the highest valued element in their capabilities set, then circumstances which cancelled their freedom to choose any functionings (ways of being) other than their highest-valued or 'maximal' wellbeing would leave their wellbeing, somewhat perversely, unaffected. For instance if a person's most valued overall wellbeing

${ }^{6}$ The consequences of Sen's distinction between wellbeing and these other objectives are considered below. 
included becoming a doctor, and yet this person became a doctor in a society where doctors were prevented from quitting to pursue any other career, then in a real sense freedom of choice has been severely curtailed even in circumstances in which the highest-valued wellbeing is achieved. Sen emphasises, too, that the valuation function for any given person "can be a partial ordering that is substantially incomplete. There is no general presumption that it is always possible to rank the values of two types of living vis-à-vis each other" (Sen 1999b: 10). It is thus an open possibility that some ways of life are not able to be ranked against each other. Whether to take up medicine, carpentry, law or music may be a choice between pursuing different available paths to personal wellbeing - and one will be chosen to the exclusion of the others - but there need be no assumption that there must exist some determinate personal wellbeing ranking between each pair.

In turning to considerations of personal freedom, Sen observes the perverse result that under his original definition, a person's maximal wellbeing appears compatible with a severely restricted capabilities set - a severe lack of freedom even in cases where all choices but the 'best' set of functionings for that person were excluded. In a footnote, Sen observes that this anomaly remains the case "unless being able to choose is an important functioning and itself affects the person's wellbeing" (1999b: 9). If wellbeing is to be defined as it has been earlier, then the value of a person's capabilities set - of the person's freedom "is given by the value of the best element in that set":

$$
\begin{aligned}
& V(S)=\max v(x) \text { (Sen 1999b: 39). } \\
& x \in S
\end{aligned}
$$

Yet the worry here is that wellbeing seems not to consist only in what a person has succeeded in doing and being, but also what he or she "could have" done (Sen 1999b: 43). Sen thus considers whether noting the extent of choices a person has across functioning vectors answers this concern. On such a theory, the more freedom of choice a person has - the more he or she 'could have' done - the better. One obvious problem with a solution such as this, however, is that no account is taken of the value in simply adding further capabilities. As Sen comments elsewhere - and as Sabina Alkire also emphasizes - "sometimes more freedom of choice can bemuse and befuddle, and make one's life more wretched" (Alkire 2005: 7; Sen 1992: 59).

An attractive solution is to include personal freedom itself as a valuable functioning - freedom of choice expressed as an activity, which is also at the same time an element of its possessor's wellbeing. Indeed, this may be the very element whose absence made the original capabilities-based definition of wellbeing, when applied reductively in terms of a person's highest-valued set of functionings, seem at odds with the pluralist thrust of the overall capabilities approach. People achieving their highest functioning but who were not really free to choose otherwise suffer from the absence not just of many capabilities but of a central functioning: the free exercise of meaningful choice between 
valuable alternative beings and doings. Sen insists that freedom as a valuable functioning should be understood in positive terms, and not just in terms of mere absence of external coercion and interference:

While 'the freedom to choose' is being valued in this format, it is important to emphasize that this 'freedom' is not being seen here in the rather 'negative' form in which it is often presented in the literature dealing with liberty and non-interference. The issue here is the positive ability to choose (Sen 1999b: 44).

Positive freedom in this sense is being capable not just of choosing from a range of alternatives, but actually going about choosing - actively, meaningfully between valuable beings and doings. For Sen, the quality of positive freedom a person commands in terms of 'substantial choosing' must also matter over and above its quantity or extent (1999b: 44-5). No merely mechanical expansion of choices between alternative beings and doings, or increase in liberty from external coercion, can stand in for this quality of positive freedom a person can exercise over his or her own wellbeing.

\section{Thick Freedom in Wellbeing and Agency}

A deep respect for the intrinsic value of freedom has emerged as a unifying element in Sen's overall approach to ethics, politics and economics. However, Sen's treatment of positive wellbeing freedom is idiosyncratic, and this idiosyncrasy has certain consequences for what might be called the 'thickness' of freedom achieved in "substantial choosing." Sen is reticent to discuss the quality of positive freedom people might exercise with respect to their own wellbeing, commenting briefly that freedom - especially of this particular stripe - is complex, ambiguous, and "not an unproblematic concept":

For example, if we do not have the courage to choose to live in a particular way, even though we could live that way if we so chose, can it be said that we do have the freedom to live that way, i.e., the corresponding capability? (Sen 2008: 273)

Sen's reluctance to address positive freedom in the sense of agency over and responsibility for wellbeing that this observation might imply is partly traceable to his strong rejection of welfarism and commitment instead to an "irreducible 'duality' in the conception of a person in ethical calculation" (1985: 41). ${ }^{8}$ Ultimately for Sen, each person is to be seen as a seeker of wellbeing, but also as a responsible agent with many other goals and commitments unrelated to personal wellbeing (Sen 1985: 203-4). Under this view, the complex interplay between 'agency freedom' and 'wellbeing freedom' often places them in direct

\footnotetext{
7 'Thick' in relation to positive wellbeing freedom is not Sen's term. 'Thick' versus 'thin' has been adapted in this context from Williams (1985: 140-3) who contrasts 'thick' value concepts such as 'gratitude' and 'brutality' with 'thin' ones such as 'wrong' and 'ought'. The distinction is closely related to that between 'aretaic' and 'deontic' concepts (see note 3 above).

${ }^{8}$ Welfarism in general is the view that all value, including moral value, is ultimately reducible to wellbeing. For Sen, welfarism means specifically the reduction of value to individual utility information, an approach prevalent in welfare economics. Welfarism in either sense is diametrically opposed to deontology.
} 
conflict, and Sen emphasises that the expression of free agency can be genuinely deleterious to people's wellbeing without being bad or wrong for the person overall (Sen 1985: 206-8).

Full personal freedom applies for Sen only to the broader sense of responsible agency and its complex interaction with life's circumstances, and thick agency freedom, at its broadest encompassing a person's whole life and 'overall conception of the good', is carefully separated from freedom regarding the much more restricted goal of personal wellbeing (Sen 1985: 203-4). Achieving wellbeing is quite strongly separable from the achievements of a person's agency goals. This distinctively deontic division of a person's normative space profoundly affects the shape 'substantial choosing' of wellbeing functions takes in Sen's overall analysis. ${ }^{9}$ One feature of particular interest is the sharp divide between an individual's responsibility, which belongs to the 'agency aspect' of a person, and their freedom to pursue personal wellbeing. To consider 'thickness' in personal wellbeing as an important feature may seem to clash with such a division, and Sen's 'thin' account casts wellbeing oddly adrift from the central commitments and responsibilities of agency that otherwise bring value to a person's life and action. However, there is a strong case for thick freedom to play a more substantial role in the capabilities approach than Sen himself entertains.

Briefly, the key to an account of thick wellbeing freedom lies in the dual nature of positive freedom as both a capability and a functioning. Positive freedom conceived as a valuable functioning in its own right manifests itself for Sen in 'substantial choice': first-person practical decision-making about what to do and be; active engagement in choosing functionings from within our current capability-set of valued beings and doings. It seems immediately obvious here that the exercise of positive freedom over capabilities itself will admit of qualitative degrees: practical choices can be made well and badly in a wide range of ways with respect to the chooser's wellbeing. This observation encompasses but also goes well beyond Sen's example of bafflement in the face of too many choices: personal wellbeing functions are implicated in most personal choice-making circumstance throughout a lifetime.

Exercising positive wellbeing freedom as both a means and end from within the complexity and uncertainty of an actual human life - one likely to be furnished with only partial and incomplete rankings between alternative beings and doings in any practical sphere - must also be a matter of possessing a set of internal resources for good choice-making that will best respond to the circumstances. If wellbeing-related choices are being made well, this adds directly, intrinsically, to a person's wellbeing, in addition to the benefits for a range of other functionings that flow from well-made choice. When choices about wellbeing are being made badly - if the free choice function is malfunctioning - then the matter is more complicated, since this disvalue must also be weighed against the value of having had the freedom to choose in the first place. Achieving the value of positive wellbeing freedom is thus to a significant extent a matter of having or lacking

\footnotetext{
${ }^{9}$ On the distinction between 'deontic' and 'aretaic' see note 2.
} 
internal resources for good choice-making, and both choosing well and choosing badly will also affect a person's wellbeing according to the capabilities approach independently of outcomes. And this observation brings Sen's capabilities approach to wellbeing back to a direct reengagement with Aristotle's account of eudaimonia. For Aristotle, doing and being well in precisely this way is not just good for a person's wellbeing, but is the chief active constituent of a perfectly well-lived human life. ${ }^{10}$

\section{Concluding Remarks: Incorporating Aristotelian Insights}

If doing well at the expression of thick positive freedom is also an intrinsically valuable element of personal wellbeing, how might its practical shape in people's lives be understood from within Sen's capabilities approach, and how might its recognition be translated into future Australian wellbeing research? A satisfactory answer to these questions is beyond the scope of this paper, but its analysis seems to suggest some potentially fruitful avenues for further inquiry. Looking beyond Sen's capabilities approach to its Aristotelian origins may provide some indication of how an enriched approach to wellbeing might be shaped with the addition of thick indicators, including the characteristics expressed in people's being and doing well with respect to their positive wellbeing freedom, that may constitute intrinsically valuable elements of their wellbeing. The recent promising move in Australian research (Saunders et al. 2008) towards 'thicker' plural indicators of social disadvantage may be seen as an early step in a more general 'thickening' of Australian personal wellbeing measures. Fresh thinking about thick freedom in Australian wellbeing and its capture in meaningful indicators promises to be an even greater challenge for empirical research, and may require the development of innovative methodologies to uncover and gauge, for instance, being 'left out' and 'missing out' with respect to thick internal wellbeing resources. Moreover, this dimension of wellbeing research need not adopt Aristotle's own views about the personal characteristics wellbeing requires, and in accepting Aristotelian insights with respect to wellbeing there is certainly no requirement to accept his or any other teleological theory of human nature. Rather, it would be better to aim - in Sen's open pluralist spirit - at capturing personal wellbeing as it is conceived of, pursued and best achieved in lives as they are actually lived, and in the process to help reorient empirical research towards tackling some of the central questions about how we are to live.

\footnotetext{
${ }^{10}$ For a comprehensive and faithful contemporary Aristotelian account of wellbeing wholly based on the ideal of human flourishing, see Kraut (2007).
} 


\section{References}

Alkire, S. (2005) Valuing Freedoms: Sen's Capability Approach and Poverty Reduction, Oxford: Oxford University Press.

Broadie, S. (2002) 'Philosophical introduction', in S. Broadie and C. Rowe (eds.), Aristotle: Nicomachean Ethics, Oxford: Oxford University Press.

Crisp, R. (2006) Reason and the Good, Oxford: Clarendon Press.

Eid, M. and Larsen, R.J. (eds) (2007) The Science of Subjective Wellbeing, New York: Guilford Press.

Finnis, J. (1980) Natural Law and Natural Rights, Oxford: Clarendon Press.

Griffin, J. (1986) Wellbeing, Oxford: Clarendon Press.

Hausman, D.M. and McPherson, M.S. (2008) 'The philosophical foundations of mainstream normative economics', in D.M. Hausman (ed.), The Philosophy of Economics: An Anthology, Cambridge: Cambridge University Press.

Hausman, D.M. (ed.) (2008) The Philosophy of Economics: An Anthology, Cambridge: Cambridge University Press.

Hursthouse, R. (1999) On Virtue Ethics, Oxford: Oxford University Press.

Kraut, R. (2007) What is Good and Why, Cambridge, Mass.: Harvard University Press.

Olsaretti, S. (ed.) (2006) Preferences and Wellbeing, Cambridge: Cambridge University Press.

Saunders, P., Naidoo, Y., and Griffiths, M. (2008) 'Towards new indicators of disadvantage: deprivation and social exclusion in Australia', Australian Journal of Social Issues, 43 (2), 175-94.

Sen, A. (1985) 'Wellbeing, agency and freedom: The Dewey lectures 1984', The Journal of Philosophy, 82 (4), 169-221.

- (1987) On Ethics and Economics, Oxford: Basil Blackwell.

- (1992) Inequality Reexamined, Oxford: Clarendon Press.

- (1999a) Development As Freedom, New York: Alfred A. Knopf.

— (1999b) 'Commodities and Capabilities', New Delhi: Oxford University Press.

- (2008) 'Capability and wellbeing', in D.M. Hausman (ed.), The Philosophy of Economics: An Anthology, Cambridge: Cambridge University Press.

Slote, M. (2001) Morals from Motives, Oxford: Oxford University Press. Williams, B. (1985) Ethics and the Limits of Philosophy, London: Fontana. 